\title{
Clothing Genre Recognition System Using Image Processing Techniques- A Survey
}

\author{
SaranyaMS ${ }^{1^{1}}$, and Geetha $\mathrm{P}^{2^{2}}$ \\ ${ }^{1}$ Anna university,Chennai,India, \\ ${ }^{1}$ saranyasivaraman5egmail.com \\ 'Anna university,Chennai,India,
}

\begin{abstract}
Nowadays, Clothing business is one of the mostimportantcomponentsinthee-commerceindustry. So, there is plenty of online clothing sites are available where people can search and retrieve the most clothing items for their user query image. Clothing genre recognition is a very active topic in computer vision and multimedia research. In the textile industry, image processing techniques provide sensitive attention in the fieldoftheimage-basedclothingrecognitionsystem. The sequence of cloth images can be given as input to the recognition system. This clothing genre recognition system helps to detect the patterns and features of cloths which helps to classify them using effective feature extraction and classification algorithms. Feature extractiontechniquescanbeusedtoobtainfeaturesfrom thecloths.Classificationalgorithmsfromsoftcomputing help to automatically classify clothes genres depending on style elements and their salient visual features. Deep learning and Support Vector Machine (SVM) classifier achieved better performance in classifying both upper wear and lower wear genres. The main motivations of this paper focus on automatically classifying both upper wearandlowerweargenrefromafull-bodyinputimage. Evaluation metrics like precision, recall, F-score were used to measure the classification accuracy.This paper addresses on issues, challenges, applications, frameworks, tools, and techniques for recognition of clothing genres is carriedout.
\end{abstract}

Keywords: Clothing Genres, Clothing Segmentation Techniques, Feature Extraction Techniques, Classification Techniques, Pattern Recognition.

\section{Introduction}

Image processing techniques provide sensitive attention in the field of clothing genres. Nowadays, online shopping is more attractive and convenient for millions of web users especially in the field of the clothing industry. One of the most essential thing for people is cloths because people wore clothes in their everyday lives. There are billions of e-commerce websites are available to satisfycustomer's needs.Human full-body images are collected from various e-commerce web- 
sites like Amazon, eBay, Zara. Human images shots can be given as input to the clothing recognition system. Real-worldhumanimagesareavailableontheinternet found to be large variations in terms of lighting conditions, image scales. These variations can be reduced by normalizing the histogram of a color image, resizing the image.Dataset preprocessing can beperformedtoremovetheheadpositionfromhuman image shots because it is considered to be less important. Body parts detection is performed to segment the upper body and lower body of the given human images using a clusteringalgorithm. Feature extraction can be performed using SIFT, SURF, Haar, HOG, LBP, and LSS for predicting predict different style elements presents in the clothing garments. Clothing Classification techniques include deep learning and Support Vector Machine (SVM) is used to classify upper wear and lower wear genres based on style element, color, texture, shape.

\subsection{Upperwear Clothing Genres}

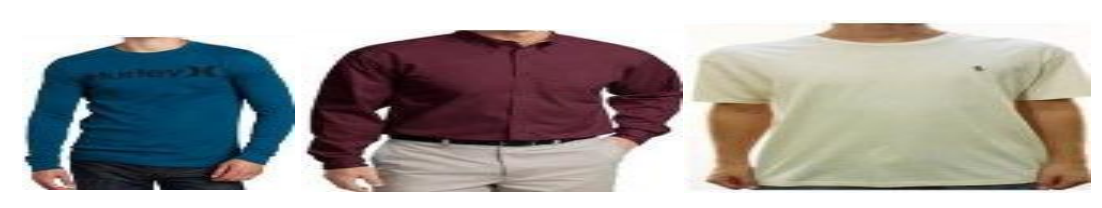

Fig. 1. Image Based Upperwear Clothing Genres

Figure 1 shows the upper wear clothing genres. Formal shirt, Informal shirt, polo shirt, T-shirt, Long-sleeved T-shirt are some of the upper wear genres. Style elements for the upper wear are Collar, Front button, Print style, Shoulder skin, Sleeve. Collar type can be collaredornotcollared.Frontbuttontypecanbeafull front button or half front button. The print style type can be plain or loud. Shoulder skin type can be exposed or covered. Sleeve type can be long sleeveor shortsleeve.

\subsection{Lowerwear Clothing Genres}
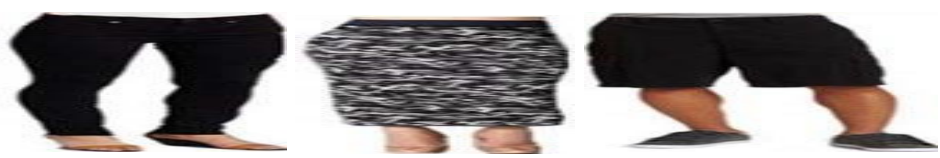

Fig. 2. Image Based Lowerwear Clothing Genres 
Figure 2 shows the lower wear clothing genres straight longskirt,Alinelongskirt,straightshortskirt,A-line short skirt, Hot pants, Trousers are some of the lower weargenres.StyleelementsforthelowerwearareLeg gap, Length, Print style,side, Pleat, Wrinkles, Width type. The leg gap type can be opening or closed. Length type can be long or short. The print style type can be loud or plain. Side type can be side or no side. Pleat type can be pleated or non-pleated. Wrinkles type can be wrinkled or smoothed. Width type can be expanded orcomparable.

The rest of the paper is organized as follows. In section, 2 discussed the detailed survey on different methods and approaches is used for recognizing clothing genres. In section 3 is summarized the various algorithms and techniques are involved in clothing recognition. In section 4 has mentioned the inferencesmadefromthesurvivedpaper.Insection5, isdescribedsomeofthefewchallengesfacedbythe clothing recognition system. Finally, the paper is concluded in section 6 .

\section{Literature Survey}

\subsection{Image based Clothing Segmentation}

Liang Xiadonet al.[5] have developed Cloths Co- Parsing (CCP) method which provides two phases of inference. The first phase called "Image Co- segmentation" and second phase called "region co- labeling". Clothing co-segmentation can be done on clothingimagesbyadoptingExemplarSupportVector Machine (ESVM) technique. Region co-labellingcan be done by using the multi-image graphical model. Finallyretrievingsimilarclothimagesforagivenuser query can be done by using the Convolution Neutral Network (CNN). Zhao Bozhaoet al.[4] have proposed a novel clothing co-segmentation algorithm (CCS)for the purpose of improving the performance of extracting clothing images from large datasets. Two phases involved in this clothing co-segmentation process. At phase 1, Foreground and background localization can be done for upper body detection, identifyingcandidateclothingregion,co-saliencymap of each image. At phase 2, clothing co-segmentation is used to co-segment the clothing region. GMMs are commonly adopted for learning and modeling the clothing images for the purpose of cosegment the clothing region. 


\subsection{Extraction of Clothing Features}

Wang Xianwanget al.[3] have proposed a reranking approach for improving search results regarding clothing attributes like a collar, button, print style, sleeve type. To achieve a reranking approach, the author used a Content Based Image Retrieval(CBIR) approach based on the bag-of-visual words (BOW) model. Dataset preprocessing steps involves face detection, clothing segmentation, skin elimination. Color code-book construction can be done using dominant color patch extraction and codebook generation. Clothing images attribute learning includes categories attribute, adjective attribute, part attributes. Clothing descriptor contains color based low-level features and attribute based high-level features for retrieving cloths matching with the user query.
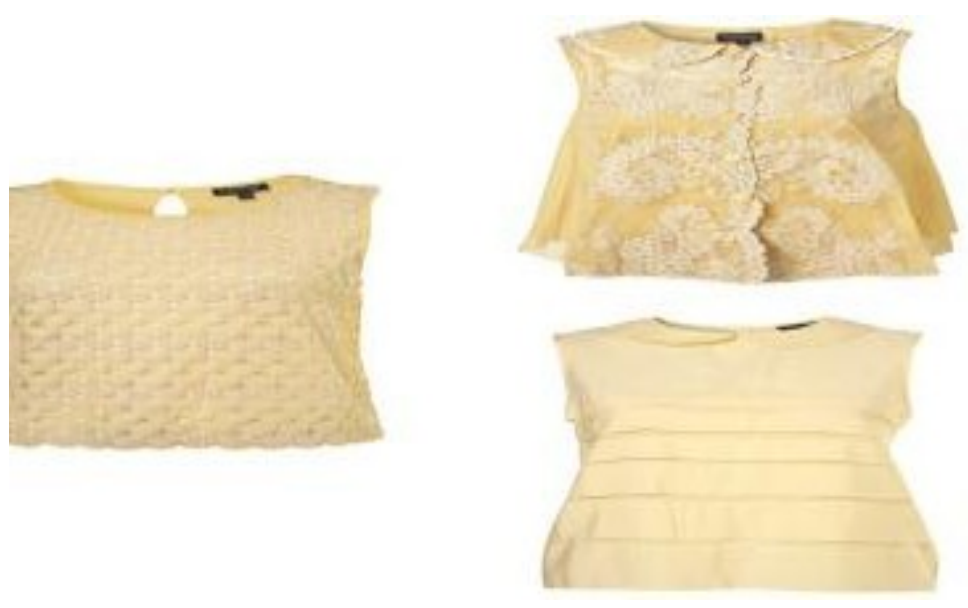

Fig. 3. Clothing Retrieval using Color Feature

Color is one of the important feature of clothing. Figure 3 shows the clothing images considering color as a feature.ShinYunheeetal.[13] haveproposedemotion predicting system for the purpose of automatically predicting human emotional concepts from a given textile images. In this paper, color and pattern of clothing images are considered as a feature. After featureextraction,k-meansclustering,NaiveBayesian 
and a Multi-layered perceptron (MLP) classifier. Out of which Multi-layered perceptron (MLP) achieved better performance in predicting emotion from textile images.

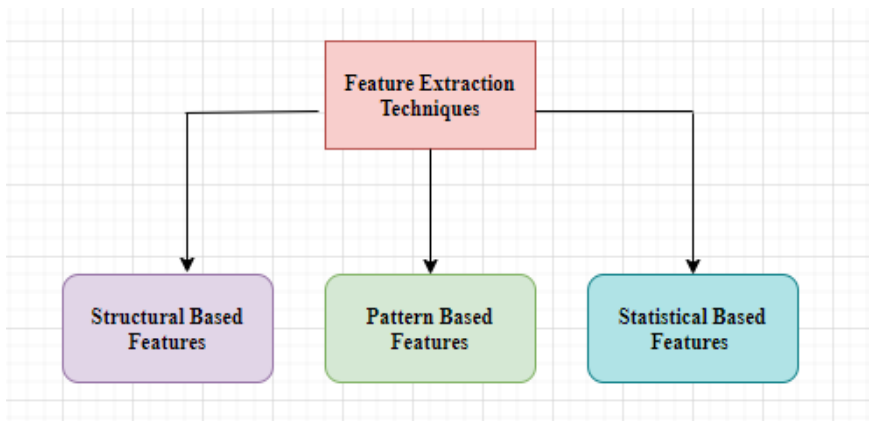

Fig.4. Feature Extraction Techniques

Figure 4describes the various feature extraction techniques.

\subsection{Image based ClothingClassification Techniques}

Nazir Met al.[10] et al have proposed an efficient gender classificationtechniqueforreal-worldfaceimages.At first, histogram equalization is used to normalize the face then extract facial portion using spatial co-the ordinate systems. Nose, mouth, eyes are the local features for face can be extracted using Local Binary Pattern (LBP). A hybrid optimization (GA-PSO) algorithm is adopted to perform gender classification. Jarin Joe Rini et al [11] have proposed automatically recognizingclothspatternsandcolors. Theyhaveused the CCNY clothing dataset. The patterns in the clothinggenresareclassifiedusingtheSupportVector Machine (SVM) algorithm.Hidayatiet al.[1] have proposed a novel approach for automatically classifying upper wear and lower wear genres based on the different style elements present on the clothing genres. For this purpose collect full-body human images from various online websites like Amazon, Zara .Then perform body parts detection using human body part detector[15][16]. Collar, print style, shoulder skin, front button, sleeve are some of the visual features for upper wear genres. Style elements for the lower wear are Leg gap, Length, Print style, side, Pleat,Wrinkles, Width type. Finally, use a multiclass supervised learning algorithm for classifying clothinggenres. 


\subsection{Clothing PatternMatching}

Yuan Shuaiet al.[7] have a proposed clothing matching system that matches both color and pattern ofretrievalimagesforuserinputqueryimage.Atfirst, color detection and matching are done by usinga normalized color histogram. At second, Gaussian smoothing is employed for pattern detection. Finally, pattern matching can be performed using gray level co-occurrence.YangXiaodongetal .66]haveproposed anovelrandomsignaturedescriptorforthepurposeof extracting global features present on the clothing pattern for visually impaired people. Camera, microphone, Bluetooth or earphone is some of the sensors used for recognizing clothing patterns. Moreover, SIFT descriptor has proven to be effective in the process of clothingmatching.

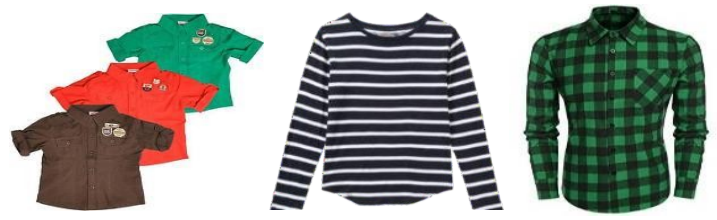

Fig.5. Clothing Pattern

Figure 5 shows the various clothing pattern like patternless, striped, plaid. Choudhury Sruti. Das et al.[9] have proposed a gait recognition method for the purposeofpredictingvariationpresentsintheclothing and carrying condition. Gait recognition is mostly used in video surveillance for identifying human activity. Gait recognition is based on Gaussian Filtering containing low pass Gaussian Filtering (LP- GF) and high pass Gaussian Filtering (HP-GF) to achieve robustness against unpredictable variation in clothing.

\subsection{Clothing Retrieval}

Megha Gupta et al.[12] have proposed a way to entry image as a query instead of using words for the purpose of retrieving similar cloths for the given user query. Dataset pre-processing is done to remove head position using the viola jones algorithm.. Then feature exaction can be performed using a Gabor filter. Finally, the classification technique is used for retrieving similar cloths images. Clothing Attribute Dataset is mainly used for promoting research in learning visual style ele- 
ments for objects. Clothing dataset contains 1856 clothing garments images with 26 ground truth is useful for extracting clothing attributes like "has collar","noncollar","short- sleeves", "long -sleeves".The labels were collected using Amazon Mechanical Turk.

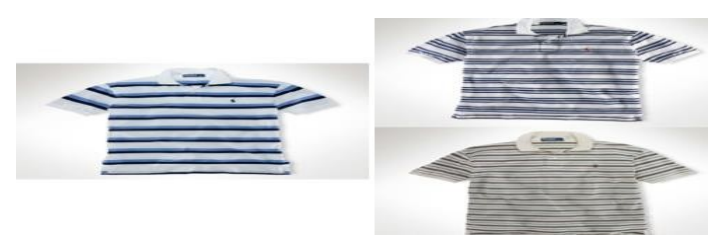

Fig.6. Clothing Pattern

Retrieving similar style clothing images based onuser queries are shown in the figure 6. Guang Sun et al. [8] have proposed part-based clothing image annotation contains tag relevance and tag saliency. Part-based clothingimageannotationisemployedtoreducenoise as well as pose variation for getting more exact candidate tags. Compared to NBVT, RANK, DIVS, Part-based clothing image annotation achieved better timecost.

\section{Analysis of Various Techniques and Algorithms In- volved in Image Based ClothingRecognition}

\begin{tabular}{|l|l|l|l|l|l|}
\hline Researchers & \multicolumn{1}{|c|}{ Algorithms } & $\begin{array}{l}\text { Meth- } \\
\text { od/ } \\
\text { Tech- } \\
\text { nique }\end{array}$ & Advantage & Disadvantage & Accuracy \\
\hline Hidayatiet al.[1] & $\begin{array}{l}\text { Deep Learn- } \\
\text { ing Support } \\
\text { Vector Ma- } \\
\text { chine Algo- } \\
\text { rithm }\end{array}$ & $\begin{array}{l}\text { Classifica- } \\
\text { tion Tech- } \\
\text { nique }\end{array}$ & $\begin{array}{l}\text { Clothing genres } \\
\text { are identified } \\
\text { based on style } \\
\text { elements }\end{array}$ & $\begin{array}{l}\text { Does not include } \\
\text { more advanced } \\
\text { features }\end{array}$ & $88.76 \%$ \\
\hline $\begin{array}{l}\text { Yamaguchi, } \\
\text { Kota et al.[2] }\end{array}$ & $\begin{array}{l}\text { Logistic } \\
\text { Regres- } \\
\text { sion Al- } \\
\text { gorithm }\end{array}$ & $\begin{array}{l}\text { Condi- } \\
\text { tional } \\
\text { Random } \\
\text { Fields(C } \\
\text { RF) }\end{array}$ & $\begin{array}{l}\text { Identifying fi- } \\
\text { ne- grained } \\
\text { clothing classes } \\
\text { without any } \\
\text { prior }\end{array}$ & $\begin{array}{l}\text { Pose estimation } \\
\text { does not handle well }\end{array}$ & $84.68 \%$ \\
\hline
\end{tabular}




\begin{tabular}{|c|c|c|c|c|c|}
\hline & & & $\begin{array}{l}\text { knowledge of } \\
\text { clothing images }\end{array}$ & & \\
\hline $\begin{array}{l}\text { Wang } \\
\text { Xianwanget } \\
\text { al.[3] }\end{array}$ & $\begin{array}{l}\text { Color match- } \\
\text { ing Algo- } \\
\text { rithm }\end{array}$ & $\begin{array}{l}\text { Content }- \\
\text { Based Image } \\
\text { Retrieval ap- } \\
\text { proach based } \\
\text { on (BOW) } \\
\text { model }\end{array}$ & $\begin{array}{l}\text { More robust to } \\
\text { pose variation, } \\
\text { illumination } \\
\text { changes }\end{array}$ & Scalability issue exists & $88.20 \%$ \\
\hline $\begin{array}{l}\text { Zhao } \\
\text { Bozhaoet } \\
\text { al.[4] }\end{array}$ & $\begin{array}{l}\text { Clothing Co- } \\
\text { Segmenta- } \\
\text { tion(CSS) } \\
\text { Algorithm }\end{array}$ & $\begin{array}{l}\text { A new Gibbs } \\
\text { energy func- } \\
\text { tion is defined. }\end{array}$ & $\begin{array}{l}\text { single image } \\
\text { segmentation } \\
\text { and multiple } \\
\text { image co- } \\
\text { segmentation } \\
\text { proven to be } \\
\text { effective }\end{array}$ & $\begin{array}{l}\text { Clothing character- } \\
\text { istics like style, lo- } \\
\text { cation constrains } \\
\text { can does not in- } \\
\text { cluded }\end{array}$ & $82.70 \%$ \\
\hline $\begin{array}{l}\text { Liang Xiado- } \\
\text { net al.[5] }\end{array}$ & $\begin{array}{l}\text { Graph } \\
\text { cuts Al- } \\
\text { gorithm }\end{array}$ & $\begin{array}{l}\text { PECS,BSC,STF } \\
\text { methods }\end{array}$ & $\begin{array}{l}\text { Accurate pixel } \\
\text { wise annotation } \\
\text { are produced }\end{array}$ & $\begin{array}{l}\text { Generic image } \\
\text { segmentation } \\
\text { does not per- } \\
\text { formed }\end{array}$ & $90.29 \%$ \\
\hline $\begin{array}{l}\text { Yang Xiao- } \\
\text { donget al.[6] }\end{array}$ & $\begin{array}{l}\text { Ran- } \\
\text { dom } \\
\text { Signa- } \\
\text { ture }\end{array}$ & SIFT,STA & $\begin{array}{l}\text { Improve the } \\
\text { life quality } \\
\text { for blind } \\
\text { people }\end{array}$ & $\begin{array}{l}\text { Do not effective for } \\
\text { large 3D transfor- } \\
\text { mation }\end{array}$ & $92.55 \%$ \\
\hline $\begin{array}{l}\text { Yuan Shuai- } \\
\text { et al.[7] }\end{array}$ & $\begin{array}{l}\text { Canny } \\
\text { edge de- } \\
\text { tection } \\
\text { algorithm }\end{array}$ & $\begin{array}{l}\text { Color detec- } \\
\text { tion and } \\
\text { matching Pat- } \\
\text { tern detection } \\
\text { and matching }\end{array}$ & $\begin{array}{l}\text { Large variation } \\
\text { and complex } \\
\text { pattern can be } \\
\text { handled }\end{array}$ & $\begin{array}{l}\text { Do not focus on } \\
\text { adding More color }\end{array}$ & $99.34 \%$ \\
\hline $\begin{array}{l}\text { GuangSunet } \\
\text { al.[8] }\end{array}$ & $\begin{array}{l}\text { Image } \\
\text { Annota- } \\
\text { tion Ge- } \\
\text { netic Al- } \\
\text { gorithm } \\
\text { (IAGA) }\end{array}$ & $\begin{array}{l}\text { NBVT,RANK } \\
\text {,DI VS }\end{array}$ & $\begin{array}{l}\text { Used part based } \\
\text { clothing image } \\
\text { annotation ap- } \\
\text { proach }\end{array}$ & $\begin{array}{l}\text { Automatic annota- } \\
\text { tion for all types of } \\
\text { clothing images } \\
\text { does not perform }\end{array}$ & $88.56 \%$ \\
\hline
\end{tabular}




\begin{tabular}{|c|c|c|c|c|c|}
\hline $\begin{array}{l}\text { Choudhury, } \\
\text { Sruti. Das et } \\
\text { al. [9] }\end{array}$ & $\begin{array}{l}\text { Rotation } \\
\text { forest en- } \\
\text { semble clas- } \\
\text { sifier }\end{array}$ & $\begin{array}{l}\text { Averaged gait } \\
\text { key phase } \\
\text { (AGKP), } \\
\text { Gaussian fil- } \\
\text { tering }\end{array}$ & $\begin{array}{l}\text { Introduced gait } \\
\text { recognition ap- } \\
\text { plication using } \\
\text { ensemble clas- } \\
\text { sifier }\end{array}$ & $\begin{array}{l}\text { More invariant } \\
\text { gait characteris- } \\
\text { tics can be in- } \\
\text { cluded to im- } \\
\text { prove robustness }\end{array}$ & $86.46 \%$ \\
\hline
\end{tabular}

\section{InferencesMade}

The inferences made from the above literature survey are listed. Most of the existingonline stores provide keyword-based or content-based search.Onlinestoresdonotwellsupportforretrieving desired style element present on the clothing genres. Most of the existing work considers only low-level features for the purpose of retrieving similar clothing images. Based on the above inferences there is a need for designing the new framework based on the upper wear and lower wear styleelements.

\section{Challenges in the image based clothing recognition}

There are lots of challenges are available for the clothing pattern identification and recognitionare listed below

- Visual object recognition is a major task under which Clothing genre recognition possess various challenges in recognizing clothing garments.

- Clothing genre recognition poses significant challenges because of having rich collection of clothing garments.

- Clothing genre recognition provides notable challenges because of the various variations in the design features present on the clothing garments.

\section{Conclusion}

This paper is given the extensive survey on various methods, approaches, and 
techniques that are involved in the recognition of image-based clothing genres. Form this surveyed result there are lots of scope for a researcher for designing a new framework for clothing recognition. Finally, this paper concludes with some of the issues and challenges in the existing methods and importance of designing a new framework for improving the result in clothing recognition using various image processingtechniques.

\section{References}

[1]Hidayati S C, You C W, Cheng W H,and Hua K L. Learning and Recognition of Clothing Genres from Full-Body Images. IEEE transactions oncybernetics.(2017).

[2] Yamaguchi Kota, Kiapour M H, Ortiz L E., and Berg, T L. (2015). Retrieving similar styles to parse clothing. IEEE transactions on pattern analysis and machine intelligence, 37(5), 1028-1040.(2015).

[3]Wang Xianwang,Zhang T, Tretter D R, and Lin Q. (2013). Personal clothing retrieval on photo collections by color and attributes. IEEE Transactions on Multimedia, 15(8),20352045.(2013).

[4] ZhaoBozhao, Wu X, Peng Q, and Yan S. Clothing cosegmentation for shopping images with cluttered background. IEEE Transactions on Multimedia, 18(6),11111123.(2016).

[5]Liang Xiadon, Lin, L, Yang W, Luo P, Huang J, and Yan, S. Clothes co-parsing via joint image segmentation and labeling with application to clothing retrieval. IEEE Transactions on Multimedia, 18(6),1175-1186.(2016).

[6]YangXiaodong,Yuan,S , and TianY. Assistive clothing patternrecognitionforvisuallyimpairedpeople.IEEETransactions on Human-Machine Systems, 44(2),234-243.(2014).

[7] Yuan Shuai., Tian Y, and Arditi A. Clothing matching forvisuallyimpairedpersons. Technologyanddisability,23(2),75- 85.(2011).

[8] GuangSun L , Wu X, and Peng, Q. Part-based clothing image annotation by visual neighbor retrieval. Neurocomputing, 213,115-124.(2016).

[9] Choudhury Sruti Das and Tjahjadi T. Clothing and carrying condition invariant gait recognition based on rotation forest. Pattern Recognition Letters, 80,1-7.(2016).

[10] Nazir M, Majid-Mirza A, and Ali-Khan S. PSO-GA based optimized feature selection using facial and clothing information for gender classification. Journal of applied research and technology, 12(1),145-152.(2014).

[11] Jarin Joe Rinis Recognizing clothes patterns and colours for blind people using neural network. In Innovations in Information, Embedded and Communication Systems (ICIIECS), 2015 International Conference on (pp. 1-5).IEEE.(2015). 
[12] GuptaM.,BhatnagarC, andJalalAS.ClothingImage Retrieval Based On Multiple Features for Smarter Shopping. Procedia Computer Science, 125,143-148.(2018).

[13] Shin Yunhee, Kim Y, and Kim E Y. Automatic textile image annotation by predicting emotional concepts from visual features. Image and Vision Computing, 28(3), 526-537. (2010).

[14] https://exhibits.stanford.edu/data/catalog/tb980qz1002.

[15]J. Dafni Rose*, K. Vijayakumar and S. Sakthivel, "Students' performance analysis system using cumulative predictor algorithm", Int. J. Reasoning-based Intelligent Systems, Vol. 11, No. 2, 2019.

[16] Vijayakumar. K, Nawaz Sherif. T, Gokulnath.S, “Automated Risk Identification using Glove algorithm in Cloud Based Development Environments", International Journal of Pure and Applied Mathematics Volume 117 No. 162017. 